Article

\title{
Beyond Left and Right: Real-World Political Polarization in Twitter Discussions on Inter-Ethnic Conflicts
}

\author{
Svetlana S. Bodrunova ${ }^{1, *}$, Ivan Blekanov ${ }^{2}$, Anna Smoliarova ${ }^{1}$ and Anna Litvinenko ${ }^{3}$ \\ ${ }^{1}$ School of Journalism and Mass Communications, St. Petersburg State University, 199004 St. Petersburg, Russia; E-Mail: \\ s.bodrunova@spbu.ru (S.S.B.); a.smoliarova@spbu.ru (A.S.) \\ ${ }^{2}$ Faculty of Applied Mathematics and Control Processes, St. Petersburg State University, 199004 St. Petersburg, Russia; \\ E-Mail: i.blekanov@spbu.ru \\ ${ }^{3}$ Institute for Media and Communication Studies, Freie Universitaet Berlin, 14195 Berlin, Germany; \\ E-Mail: anna.litvinenko@fu-berlin.de \\ * Corresponding author
}

Submitted: 17 December 2018 | Accepted: 22 April 2019 | Published: 9 August 2019

\begin{abstract}
Studies of political polarization in social media demonstrate mixed evidence for whether discussions necessarily evolve into left and right ideological echo chambers. Recent research shows that, for political and issue-based discussions, patterns of user clusterization may differ significantly, but that cross-cultural evidence of the polarization of users on certain issues is close to non-existent. Furthermore, most of the studies developed network proxies to detect users' grouping, rarely taking into account the content of the Tweets themselves. Our contribution to this scholarly discussion is founded upon the detection of polarization based on attitudes towards political actors expressed by users in Germany, the USA and Russia within discussions on inter-ethnic conflicts. For this exploratory study, we develop a mixed-method approach to detecting user grouping that includes: crawling for data collection; expert coding of Tweets; user clusterization based on user attitudes; construction of word frequency vocabularies; and graph visualization. Our results show that, in all the three cases, the groups detected are far from being conventionally left or right, but rather that their views combine anti-institutionalism, nationalism, and pro- and anti-minority views in varying degrees. In addition to this, more than two threads of political debate may co-exist in the same discussion. Thus, we show that the debate that sees Twitter as either a platform of 'echo chambering' or 'opinion crossroads' may be misleading. In our opinion, the role of local political context in shaping (and explaining) user clusterization should not be under-estimated.
\end{abstract}

\section{Keywords}

echo chamber; inter-ethnic conflict; political polarization; social media; Twitter

\section{Issue}

This article is part of the issue "Public Discussion in Russian Social Media", edited by Olessia Koltsova (Higher School of Economics, Russia) and Svetlana Bodrunova (St. Petersburg State University, Russia).

(C) 2019 by the authors; licensee Cogitatio (Lisbon, Portugal). This article is licensed under a Creative Commons Attribution 4.0 International License (CC BY).

\section{Introduction}

Today, social polarization is believed to be growing both along traditional and newer lines along which schisms form (Duca \& Saving, 2017), of which political ones are, arguably, the sharpest. Despite the ever-increasing body of knowledge on political attitudes and alignments online, we still lack understanding of how political divisions show up in issue-oriented discussions and whether there is a cross-country pattern.

Despite all the well-described representation distortions (Daniels, 2013), the content of social media is still used for predicting consumer and/or electoral choices (Colleoni, Rozza, \& Arvidsson, 2014), and the studies of political polarization on social media, including Twitter, are growing in popularity (Barberá, 2014). However, 
there are several shortcomings in today's studies of political polarization in user-generated content.

Thus, in most cases, audience polarization is studied by examining purely political issues or events, while social conflicts of race, gender or religious origins with both evident and idiosyncratic polarization and politicisation (McCright \& Dunlap, 2011) are rarely studied. Due to context and language differences, multi-country studies are also rare, especially where both established democracies and countries beyond the Euro-Atlantics are included, as, for most observers, these remain politically incomparable. However, conditions other than political regimes may create grounds for cross-cultural juxtapositions (Bodrunova, Litvinenko, \& Blekanov, 2018; Bodrunova, Blekanov, \& Maksimov, 2017).

Another conceptual limitation is that, even in the most advanced studies, the detection of users' political affiliations or ideologies is done via proxies, most often via structural network factors, such as: friendship affiliations; patterns of following (Barberá, Jost, Nagler, Tucker, \& Bonneau, 2015; Rivero, 2017); or content sharing (Colleoni et al., 2014), which could be misleading. Addressing this gap, newer works show that group polarization in social media may be studied by looking at user texts, including complex referrals to specific phenomena that matter for group identity (Evolvi, 2017). We argue that the analysis of political divisions needs to unite both structural and content aspects (Bodrunova, 2018).

In order to bridge these gaps in previous studies, we look at Twitter discussions regarding inter-ethnic clashes; they have similar conflict triggers and structure of social groups involved into conflict (Bodrunova, Litvinenko, \& Blekanov, 2017). Whilst avoiding making straightforward comparisons, we explore users' political polarization and suggest a mixed method to detect it across three cases in different political regimes: the USA; Germany; and Russia. By the UN estimates of 2013-2017, these countries have recently been the three most attractive countries to migrants in the world (United Nations, 2013, 2017) and have all witnessed violent inter-ethnic clashes that became global trending topics on Twitter.

This article, thus, is organized as follows: In Section 1, we review the approaches of assessing user polarization on social media and the conflicts under our scrutiny. In Section 2, we formulate the research questions and describe our methodology. In Section 3, we provide the results; in Section 4, we interpret and discuss them.

\section{Political Polarization on Twitter: The Current State of Research}

\subsection{Political Polarization Studies and the Current Research Gaps}

Throughout recent years, mixed evidence has persisted in social media studies on whether users go online to agree or to argue (Yardi \& Boyd, 2010). Research into echo chambers (Colleoni et al., 2014; Sunstein, 2002) has shown that user homophily, both structurally and semantically, may prevent the formation of online 'opinion crossroads', as there is 'evidence of persistent ideological sorting in online communication networks' (Barberá, 2014 , p. 2). However, a range of works point to the opposite effects in Twitter communication, with weaker ties responsible for the diversification of the consumption of political information (Barberá, 2014) as well as different platform features on Twitter leading simultaneously to echo chambers and inter-community communication (Conover et al., 2011). Thus, evidence suggests more research is needed to assess the patterns of users' political clusterization on social networks.

Until today, most Twitter polarization studies are bound to the one-country-one-case strategy-with a few notable exceptions (Barberá, 2014; Barberá et al., 2015). Another problem arises from today's understanding of online political polarization (Bramson et al., 2016) as a situation when 'a social or political group is divided into two opposing sub-groups having conflicting and contrasting positions, goals and viewpoints, with few individuals remaining neutral or holding an intermediate position' (Guerra, Meira, Cardie, \& Kleinberg, 2013, p. 215; cf. Isenberg, 1986; Sunstein, 2002).

Empirical evidence suggests that, if a heterogeneous group containing users with two opposing views has a non-zero cross-view retweet rate, it will end up as two polarized communities (Conover et al., 2011). Following this logic, the studies of political polarization result in predefined binary descriptions of polarized communitiessee Morales, Borondo, Losada, and Benito (2015) for Venezuela; Agathangelou, Katakis, Rori, Gunopulos, and Richards (2017) for Greece; or Weber, Garimella, and Batayneh (2013) for Egypt.

However, for studies beyond the two-party electoral process, it seems useful to remember that polarization is an individual case of clusterization along schismatic lines, disregarding the number of resulting clusters (Esteban \& Ray, 1994). In social conflicts, conflicting groups are not necessarily structured along binary political party divisions. The classic work of Tajfel and Turner (1979) shows how social identity (including ethnic identity) divides in- and out-groups, while a later normative model of dissent in social groups (Packer, 2008) implies that, in inter-ethnic conflicts, the majority may divide into prominority and anti-minority clusters if the anti-minority attitude is perceived as harmful to the collective (Packer \& Chasteen, 2010, p. 5). Also, the very political spectra may be highly multi-dimensional, as The Manifesto Project (https://manifesto-project.wzb.eu/) or Polity Project (http://www.systemicpeace.org/polity/polity4.htm) suggest. Thus, we consider polarization more as multi-polar fragmentation of divergent clusters, of which bipolar clusterization is just an option.

Non-bipolar clusterization seems to be especially probable for 'issue' or 'ad hoc' publics (Bruns \& Burgess, 2011; Papacharissi, 2015) that emerge on social networks. This claim is supported by research on the 
topic and issue-based discussions (Elgesem, Steskal, \& Diakopoulos, 2015). In single case studies, user polarization has been studied in regard to abortion, samesex marriage, gun control, and climate change (Elgesem, 2017; Guerra et al., 2013; Yardi \& Boyd, 2010), with varying degrees and directions of polarization detected. Moreover, there is a clear difference in polarization patterns between political and non-political issues (Barberá et al., 2015). But the evidence of differences in polarization patterns is still scarce in academic literature.

The biggest challenge in today's polarization studies is that instead of taking into account the actual content of user posts, detection of users' political affiliations is conducted via proxies. Of those, the most interesting results come from assessing structural network factors such as friendship affiliations (Barberá \& Rivero, 2015), retweeting patterns (Guerra, Veloso, Meira, \& Almeida, 2011), patterns of political following (Barberá et al., 2015; Rivero, 2017) or content-sharing patterns (Adamic \& Glance, 2005; Bakshy, Messing, \& Adamic, 2015; Colleoni et al., 2014; Elgesem, 2017). However, using proxies may be misleading (Adamic \& Glance, 2005) and even express analysis of actual tweets shows the extreme diversity of political views, both in the form of direct expression and in opinionated content.

However, if not proxies, then what? Several studies suggest that group polarization in social media may be examined by analysing complex user referrals to phenomena that matter for their identity and group alignment (Evolvi, 2017), as it is how the attitudes are expressed in natural language. In the simplest possible terms, one would take user attitudes (positive, negative, and neutral) towards particular objects for such referrals.

Thus, we will try to construct group divisions from the actual Tweet content by coding user referrals towards political players and then defining which of these attitudes divide the users most, and for how many clusters.

\subsection{Lexicon-Based Approaches to the Analysis of User Polarization}

The area of research closest to our idea of bringing content into polarization studies is a lexicon-based analysis of Twitter data. In recent years, the field has experienced explosive growth, predominantly based on the analysis of sentiments. Without delving fully into these methodologies, we will simply note that the possibility of use of vocabulary-based approaches for polarization assessment tasks (Hillmann \& Trier, 2012) is usually based on combining lexical and structural analysis. Several researchers went beyond so-called 'naïve' sentiment and have tried to link affect (Stieglitz \& Dang-Xuan, 2012) or appraisal (Dang-Xuan, Stieglitz, Wladarsch, \& Neuberger, 2013) in user texts, types of lexical units (Speriosu, Sudan, Upadhyay, \& Baldridge, 2011), and structural elements of Twitter discussions, like graphs of following or speed and volume of Tweet dissemination. Using these and other works, one could conclude that a sentiment-based approach to detecting left and right differences would imply developing a 'negative' (say, leftist) + neutral + 'positive' (say, rightist) lexicon and applying them to the discussion bulk. However, the problem that we have run into with this approach is the following:

(1) The users expressed not 'left views' or 'right views' but attitudes (with their lexical markers) towards politicians, institutions, social groups, or events ('actors');

(2) A given user would express attitudes towards not just one but many actors of different political stances;

(3) The same user could express recognizedas-rightist attitudes towards one actor and recognized-as-leftist attitudes towards another actor of comparable significance (e.g., immigrants and nationalists);

(4) The same user could express negative views on both leftist and rightist actors (say, Barak Obama and the KKK in the USA).

In case (3), the user's preferences, as measured by onedimensional positive/negative sentiment analysis, would create a zero-sum, and assigning the bias would not be possible. In case (4), an at least two-dimensional measurement of the political spectrum is needed. Taking this into consideration, we have further developed our research questions and the exploratory research design based on user sentiment, but not on pre-defined targetindependent lexicons. Instead, to better capture user attitudes, we will use expert coding of Tweets, standardising the coding process with the help of the idea of 'complex user referrals' by Evolvi (2017).

\subsection{The Research Cases}

As stated above, we have studied three intergroup conflicts of ethnic or racial origins in the three leading immigration recipient countries: the USA, Germany, and Russia. Direct comparisons of ad hoc discussions (Bruns \& Burgess, 2011) are currently viewed with some doubt in academic literature. Without developing a strictly comparative research design, we have argued elsewhere (Bodrunova, Litvinenko, \& Blekanov, 2017; Bodrunova, Blekanov, \& Maksimov, 2017) that the conflicts we picked for the analysis are similar enough as research cases. They share a range of attributes: a violent interpersonal trigger, outbursts of public discussion across media platforms (becoming trending topics on Twitter), social polarization along the inter-ethnic or inter-race chasms, street action, and involvement of federal authorities. In addition, they were chosen because they were the first in a line of similar conflictual cases and, at least partly, set the communicative patterns for later discussions.

The cases are described as follows:

1) A violent uprising against immigrants from Central Asia in the district of Biryulyovo, Moscow, Russia, in 
September 2013. After immigrant Orkhan Zeinalov, allegedly, killed local youngster Egor Scherbakov, the Biryolyovo residents destroyed the local warehouse and a trade centre around which hundreds of illegal immigrants had been dwelling. Several non-violent 'people's gatherings' followed.

2) Ferguson riots, Missouri, USA, in August 2014. There, unarmed African American teenager, Mike Brown was shot to death by white police officer Darren Wilson. The killing, as well as the defensive behaviour of the local police department, spurred several waves of street protests and peaceful support actions, including crowds at Mike Brown's funeral ceremony.

3) Mass harassment and rape of females on New Year's Eve of 2016 in Cologne, Germany. Over 1,000 women reported being harassed during the celebrations on the city's main square, allegedly, by re-settlers from North Africa and the Middle East. After that, demonstrations in protest were organized by radical political actors (PEGIDA movement and the party 'Alternative for Germany').

\section{Research Questions and Methodology}

\subsection{The Outline of the Research Design}

\subsubsection{Research Questions}

From what was said above, we have formulated the following research questions:

RQ1. How, if at all, do the users cluster within the discussions, based on their attitudes to the major conflict actors? Does binary clusterization best describe user grouping?

RQ2. Can the clusters be described as left or right in relation to the respective national political spectra? If not, then how could these clusters be described?

$R Q 3$. Are there similarities in the cluster structure of the discussions?

\subsubsection{The Research Design}

The way the RQs were formulated demanded an exploratory research design. To answer the research questions, we had to see which user groups emerged among the influencers and what discourses they conveyed.

Our concept for detecting user polarization was that political grouping within a discussion was constructed via a multi-dimensional combination of attitudes towards political actors (as defined above). These major political actors needed to be deduced from the discussions themselves. Then, the attitudes towards these players would be decrypted by expert coders for the key users, or influencers (Bodrunova, Blekanov, \& Maksimov, 2017), usually the bearers of the spectrum of attitudes.

The data received after coding would undergo clusterization, with each user belonging to one non-fuzzy cluster. Tweets by the users in the detected clusters would provide the word frequency vocabularies, which, after expert assessment, would turn into clusterization vocabularies. The latter would then be applied to all the users in the discussions, to see which users get into clusters and which discourses form there.

This approach, even if simple enough and reliant on expert intrusion, allows us to take into account the nature of the users' political discussion, as well as the lack of linearity of their political positioning. We consider this crucial for studies on conflict discussions, as it may allow the inclusion of conflict-invoked (e.g., pro- or antiminority), actor-oriented (e.g., authorities), and traditional political divisions (e.g., left and right and centre and radical). At this exploratory stage, our method does not imply machine learning or supervised approaches to data classification; we use big datasets at this stage of data collection only.

\subsection{The Research Procedures}

\subsubsection{Data Collection and Pre-Processing}

As this work is part of a bigger research project, our methods of data collection were described in detail previously (Bodrunova, Litvinenko, \& Blekanov, 2017). Here, we briefly describe the steps we followed.

We used trendinalia.com to detect the initial discussion keywords and snowball reading to amplify this collection, thus forming the vocabularies for crawling. Trendinalia.com is a web service that allows daily monitoring of both world, regional, and national Twitter trending hashtags and words with no hashtag on an hourly basis, with the possibility of backdating; it has worked best in terms of detecting the trending topics, compared to the over ten other websites we had tried since 2013.

Using an API-independent Twitter crawler (Blekanov, Sergeev, \& Martynenko, 2012), we collected the content of the discussions. All publicly available Tweets and the data on user interactions (likes, retweets, comments) were collected by a two-step procedure. Step one included the users who posted under the hashtags. Step two detected a wider community of likers, retweeters and commenters. On the discussion graph, only the step one nodes have been visualized.

Due to reasons regarding feasibility and sample comparability, collection periods differed. Thus, for Russia and Germany, the download period was 30 days after the trigger event. For the USA, we had to select the two weeks following the shooting, with Mike Brown's funeral as the central event. The user samples included:

For Biryulyovo-Step1: over 3,700 users; Step2: over 12,000 users;

For Ferguson-Step1: over 70,000 users; Step2: over 210,000 users;

For Cologne-Step1: over 12,000 users; Step2: over 99,000 users. 


\subsubsection{Data Analysis}

To answer RQ1, we needed to cluster key users by their political views, define the cluster vocabularies, and apply these vocabularies to the rest of the users, in order to see the discussion clusters and interpret their discourses.

As we expected the influencers to be bearers of the polarizing discourse, for each case, we defined the group of influencers based on nine parameters: the number of Tweets, likes, retweets, comments, in-degree, outdegree, degree, betweenness, and pagerank centralities. After these experiments, using various thresholds, the top 50 users were chosen as the cutting line for each parameter. As many users were repeated in the top due to several specifications, the duplicates were deleted. After elimination of influencers with low numbers of Tweets and bot-like influencers (with a percentage of repeated Tweets over 50\%) 156 users for Germany, 105 users for Russia, and 105 the USA were left. But, for the USA sample (which was several times bigger in the number of Tweets), the number of users was reduced by half, to 52 users. Their respective tweet collections for reading and coding included 13,359, 3,012, and 9,540 tweets.

To define user attitudes towards political actors, we developed scales for coding and coded the users (not their Tweets). The coders were experts in inter-ethnic conflict and, additionally, academic native-speakers, and the level of inter-coder reliability as measured by Cohen's kappa reached at least 0.68 for any two sub-samples. The coders used the scale from -2 to 2 to assess the attitude of each user to the following groups that had been identified as attitude triggers by reading the tweets before coding: 1) the minority (immigrants or African Americans); 2) 'radical right' or 'radical white' - nationalists in Russia, PEGIDA and AFD in Germany, and the Tea Party and the KKK (as a label for radical whites) in the USA; 3) the incumbent country leaders-Vladimir Putin and Dmitry Medvedev in Russia, Angela Merkel in Germany, and Barak Obama and Hillary Clinton in the USA; 4) local authorities and police forces grouped together as the 'oppressive and responsible' actors. Attitudes towards liberal opposition in Russia and to Republicans and Democrats were also coded, as we found them salient in the Tweets.

Based on this coding, the influences were clustered to form groups with similar combinations of attitudes. After clustering, the Tweets of each group were merged, and fully divergent frequency vocabularies of their discourses were formed with the use of expert vocabulary 'cleaning'. Then, we applied the vocabularies to all the users in the discussions, to see how the discourses distribute within the discussion structure. We also measured whether these discourses formed distinct nebulae; but even if they did not, we assessed which users belonged to these discourses and interpreted the semantics of their speech qualitatively. What mattered for our analysis was whether the influencers formed distinct groups; all the following steps were the consequence.
In detail, the research steps were the following.

1) Based on our coding, the influences of each case were grouped with the help of a k-means clustering algorithm with sorted the distances. With the number of clusters and the number of variables being diverse, the best solutions were finally chosen based on Silhouette metric $S$, within- and between-cluster square sums, examinations of variable means in each cluster (see Figures 1 to 3 for Russia, Germany, and the USA, respectively), and expert reading of tweets in each cluster. All the three influencer groups clustered well; Germany clustered best, Russia followed, and the USA the least, but all the solutions were sufficient by Silhouette from 2 to 10 possible clusters. To identify the best solutions, other aforementioned metrics were used. Those solutions were:

For Russia: 4 variables (attitude to liberal opposition excluded), 3 clusters of 49,36 , and 20 users, $S>0.4$; For Germany: 4 variables, 3 clusters of 99,48 , and 9 users, $S>0.5$;

For the USA: 5 variables (attitude to Democrats excluded), 4 clusters of $15,15,12$, and 10 users, $S>0.2$.

2) For each cluster, word frequency vocabularies were formed by merging the Tweets, ranging the words by frequency, and expert reading. After reading, only the words unique or highly characteristic for each cluster (for example, two mentions in one cluster and 160 in another would result into eliminating the word in the first one and leaving it in the other). If the difference between the numbers of mentions in any two clusters of the case was smaller than ten times, the word was eliminated in all the clusters.

3) We applied the thesaurus to the rest of the users in each case; we wanted to identify the users who use the words from the divergent thesauri. As a result, we have received three types of users in each case: 1 ) the users who belonged to clusters 1 to 3 or $4 ; 2$ ) the 'overlappers' who used the language of more than one cluster; 3 ) the users who did not use the discourses (mostly due to a low number of their Tweets). To ensure a higher quality of marking users, rather than using individual words from the thesauri, two-word combinations were used.

4) Based on this information, we constructed the graphs of discourse distribution, with users as apexes and user interactions (comments and/or retweets) as edges, and calculated the indices for user centralities. We assessed who were the most influential discourse bearers and what they spoke about. We used Gephi algorithms OpenOrd and Force Atlas 2 for graph construction (see Martin, Brown, Klavans, \& Boyack, 2011, on OpenOrd), as the former favours centripetal graphing and the latter better shows visual homophily (see Figures 4 to 6 ). To see whether the groups bearing the discourses were tighter than inter-group connections, we calculated the mean number of in-group and inter-group edges.

To answer RQ2 about the left or right nature of the clusters, we partly recoded our coding data and cor- 
rected the graphs of means (Figures 1 to 3 ) accordingly. Recoding was needed to re-interpret attitudes for and against a given actor as pro-left or pro-right. E.g., the influencers expressed attitudes towards political leaders (Obama, Merkel, and Putin), coded -2 to 2. But, for the respective political spectra, Obama is leftist, while
Merkel and Putin (Bluhm \& Varga, 2018) represent the rightist spectrum side. To 'normalize' the user attitudes, we recoded all the pro-left views as -1 to -2 , and all pro-right views as 1 to 2 (see Table 1). By doing this, we could show on the graphs of means whether the clusters (and how many of them) were pro-left, pro-right, or

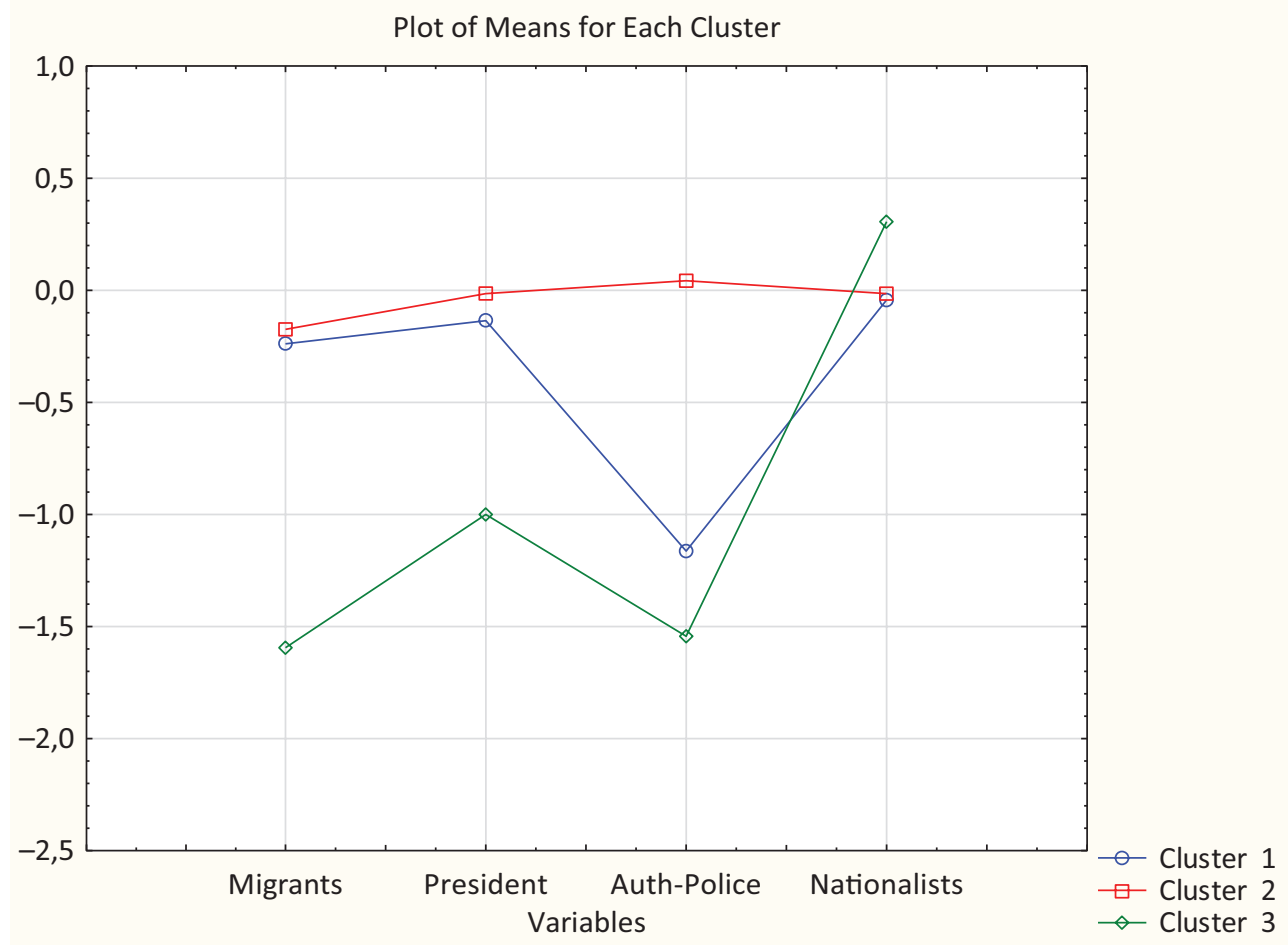

Figure 1. Mean values of user attitudes to the selected political actors in attitude-based clusters for Russia.

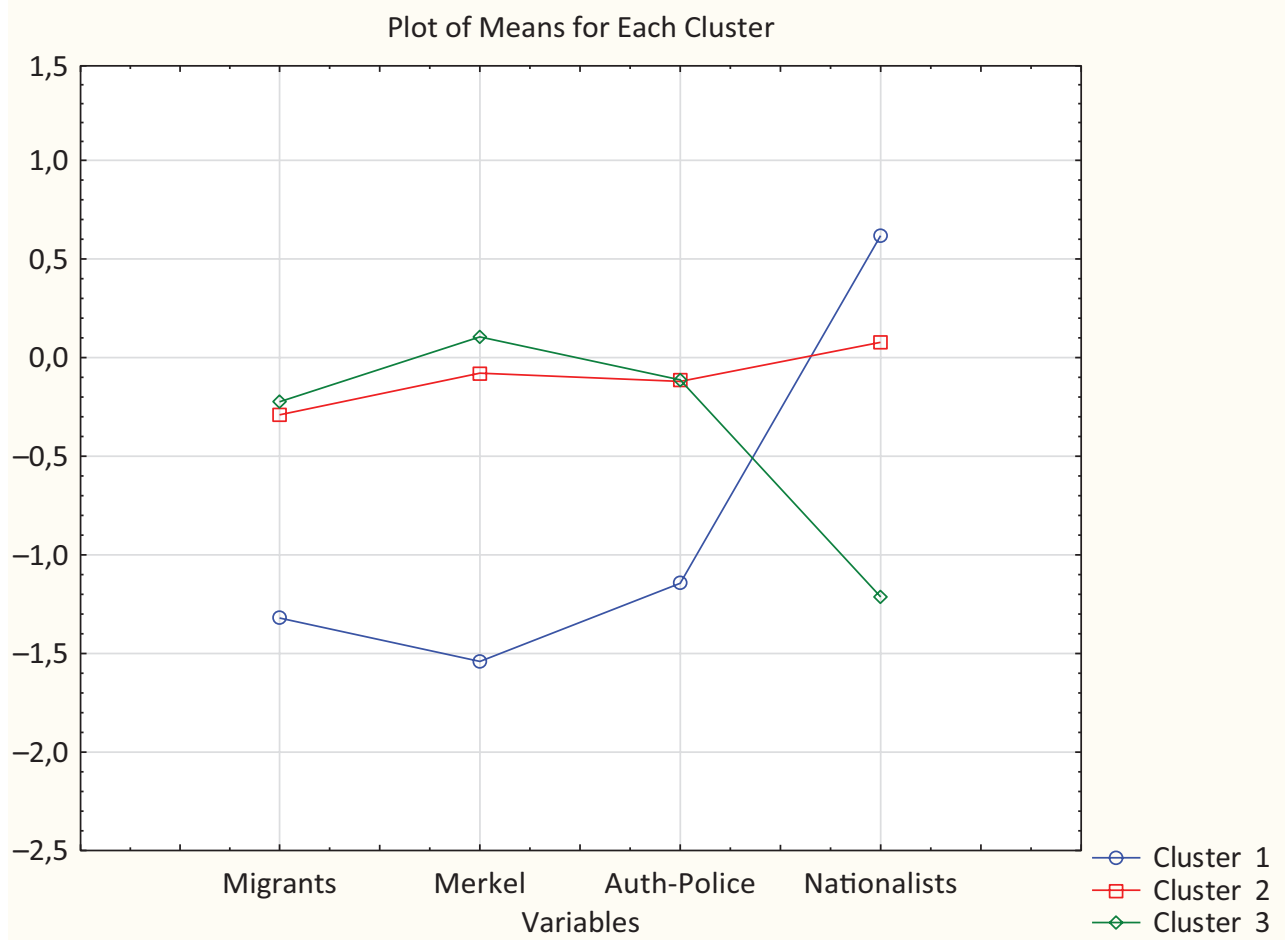

Figure 2. Mean values of user attitudes to the selected political actors in attitude-based clusters for Germany. 


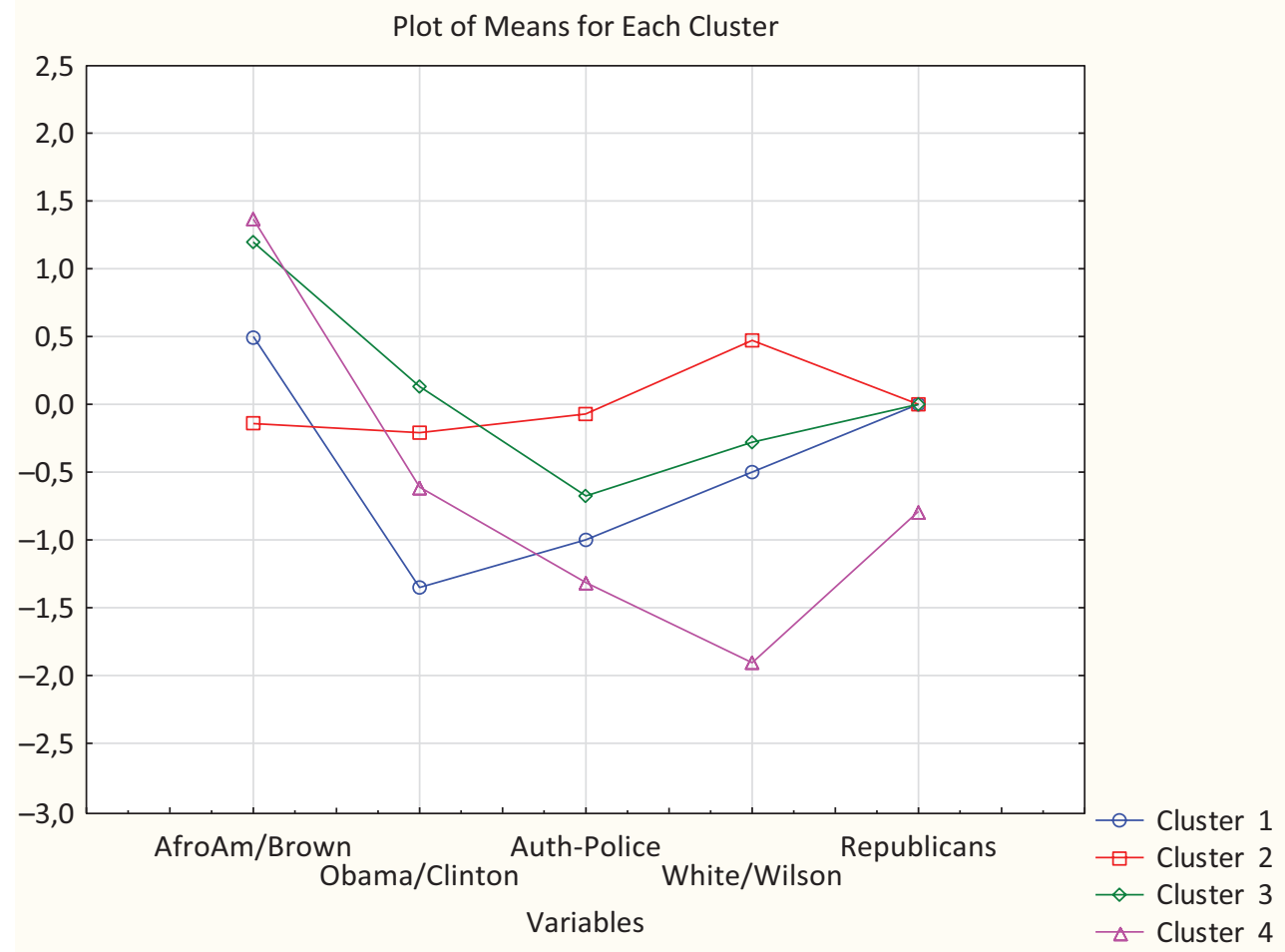

Figure 3. Mean values of user attitudes to the selected political actors in attitude-based clusters for the USA.
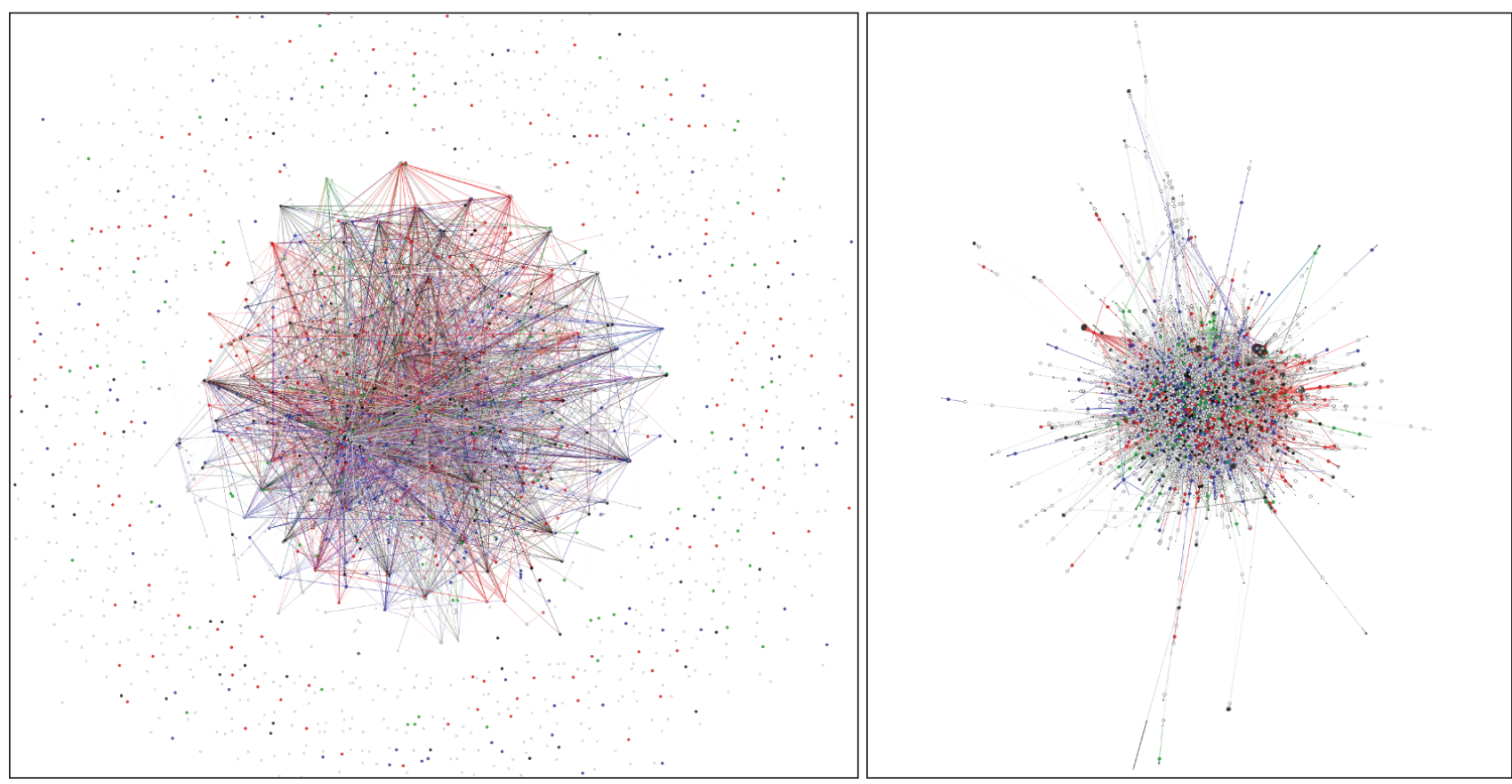

Figure 4. Communication within and between discursive groups of users in the discussions, with users as vertices and interactions (retweets and comments) as edges; reconstructed by OpenOrd and Force Atlas 2 algorithms for Russia. Notes: blue: Cluster 1, 'anti-establishment nationalists'; red: Cluster 2, 'news disseminators'; green: Cluster 3, 'angry citizens'; black: 'overlappers'; grey: non-clustered users. 


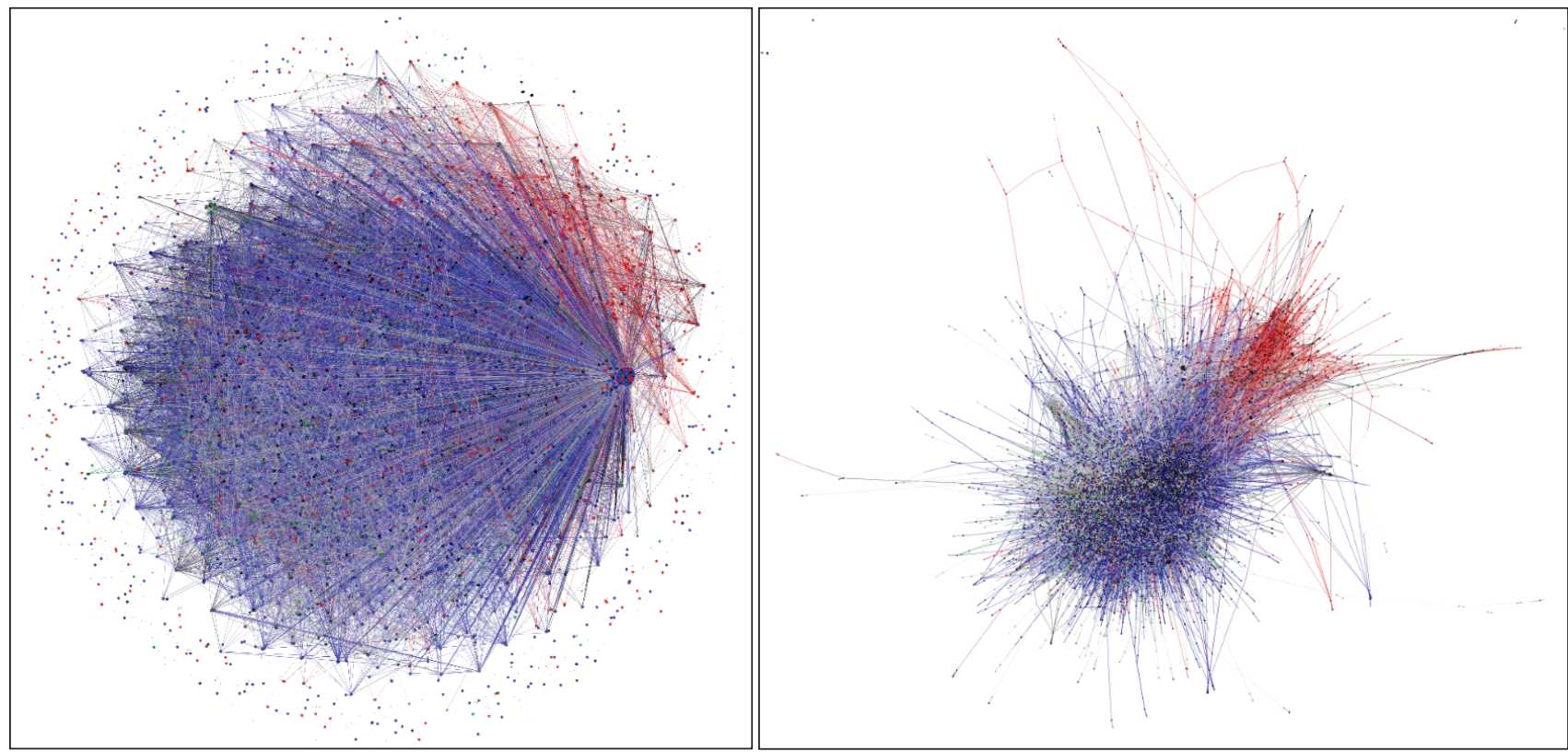

Figure 5. Communication within and between discursive groups of users in the discussions, with users as vertices and interactions (retweets and comments) as edges; reconstructed by OpenOrd and Force Atlas 2 algorithms for Germany. Notes: blue: Cluster 1, 'nationalists'; red: Cluster 2, 'news disseminators'; green: Cluster 3, 'anti-nationalists'; black: 'overlappers'; grey: non-clustered users.

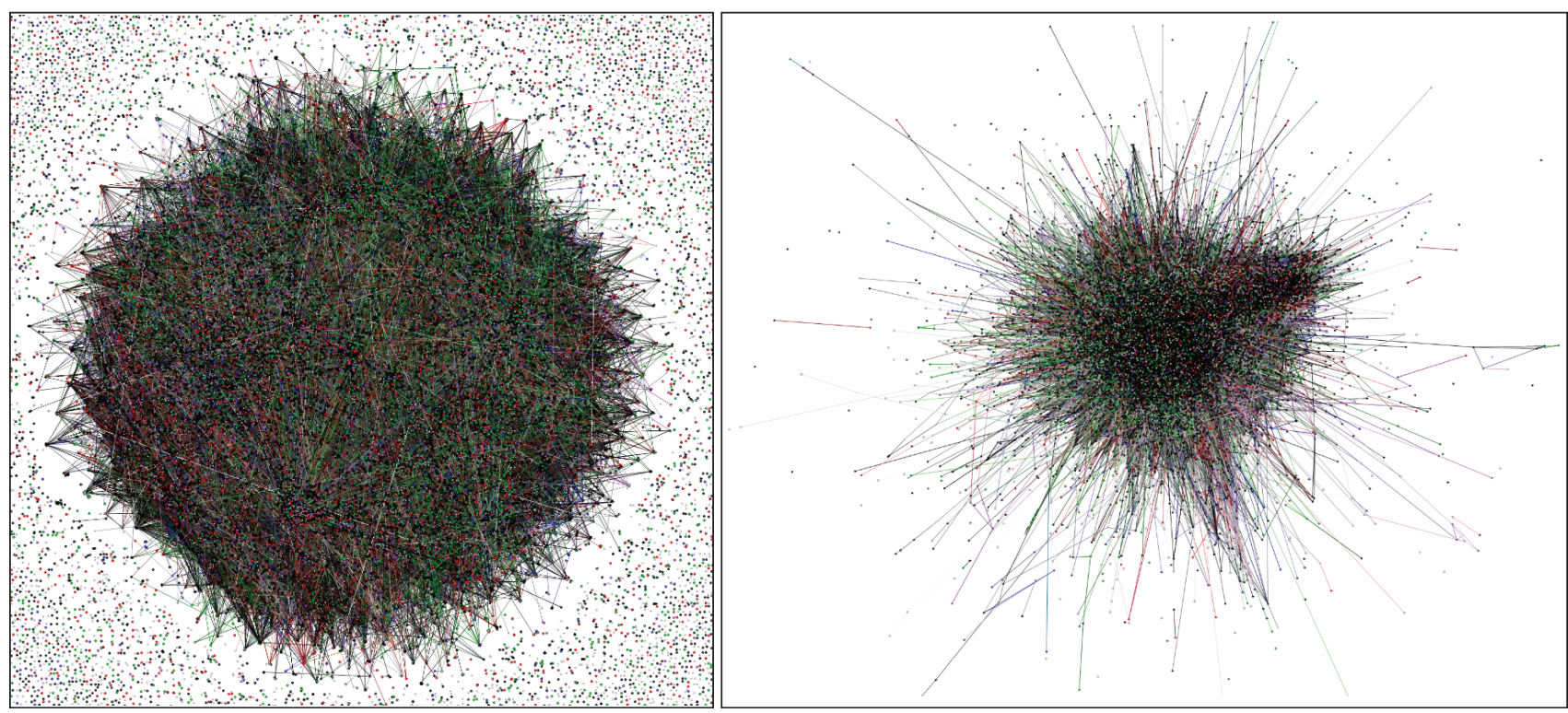

Figure 6. Communication within and between discursive groups of users in the discussions, with users as vertices and interactions (retweets and comments) as edges; reconstructed by OpenOrd and Force Atlas 2 algorithms for the USA. Notes: blue: Cluster 1, 'politicized observers'; red: Cluster 2, 'media-oriented users'; green: Cluster 3, 'human rights activists'; purple: Cluster 4, 'whites' blamers'; black: 'overlappers'; grey: non-clustered users.

mixed-see Figures 7 to 9 for Russia, Germany, and the USA, respectively.

To answer RQ3, we qualitatively assessed the results for RQ1 and RQ2.

\section{Results}

Our results show that the discourses identified by coding influencers cover a substantial part of the discourse in all the cases: for Russia, the thesauri covered $31,5 \%$, in Germany, $63,4 \%$ and, in the USA, $73,5 \%$ of the users. This shows that influencers' talk reflects the discourse of 'ordinary users' to different extents in each country, but everywhere we were able to detect the discourses that were important for the overall discussion.

As the figures suggest, in all the three cases, group structure was not binary; moreover, binary solutions for each country would hide important discourses that 


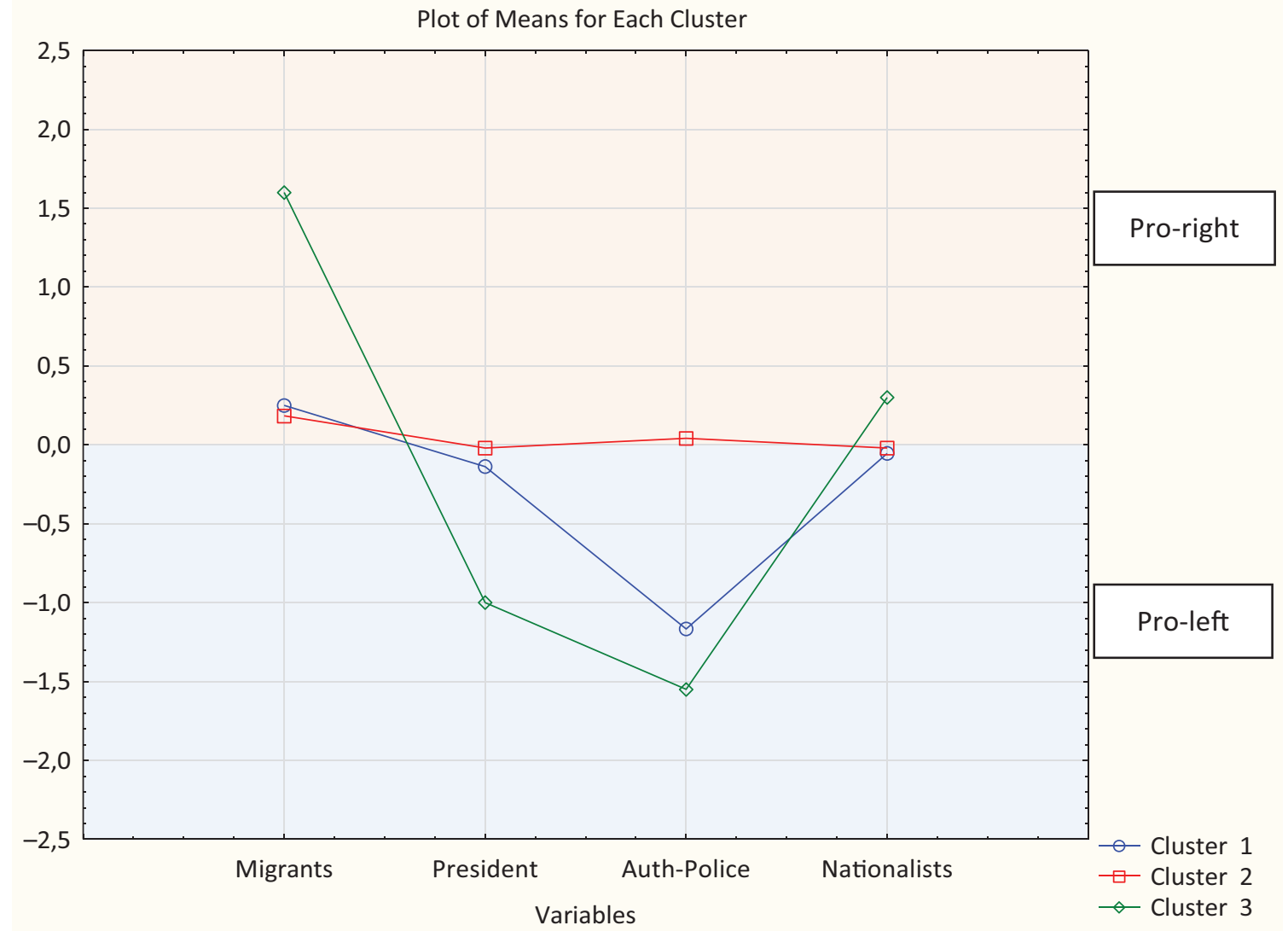

Figure 7. Mean values for the recoded data on user attitudes towards the selected political actors for Russia.

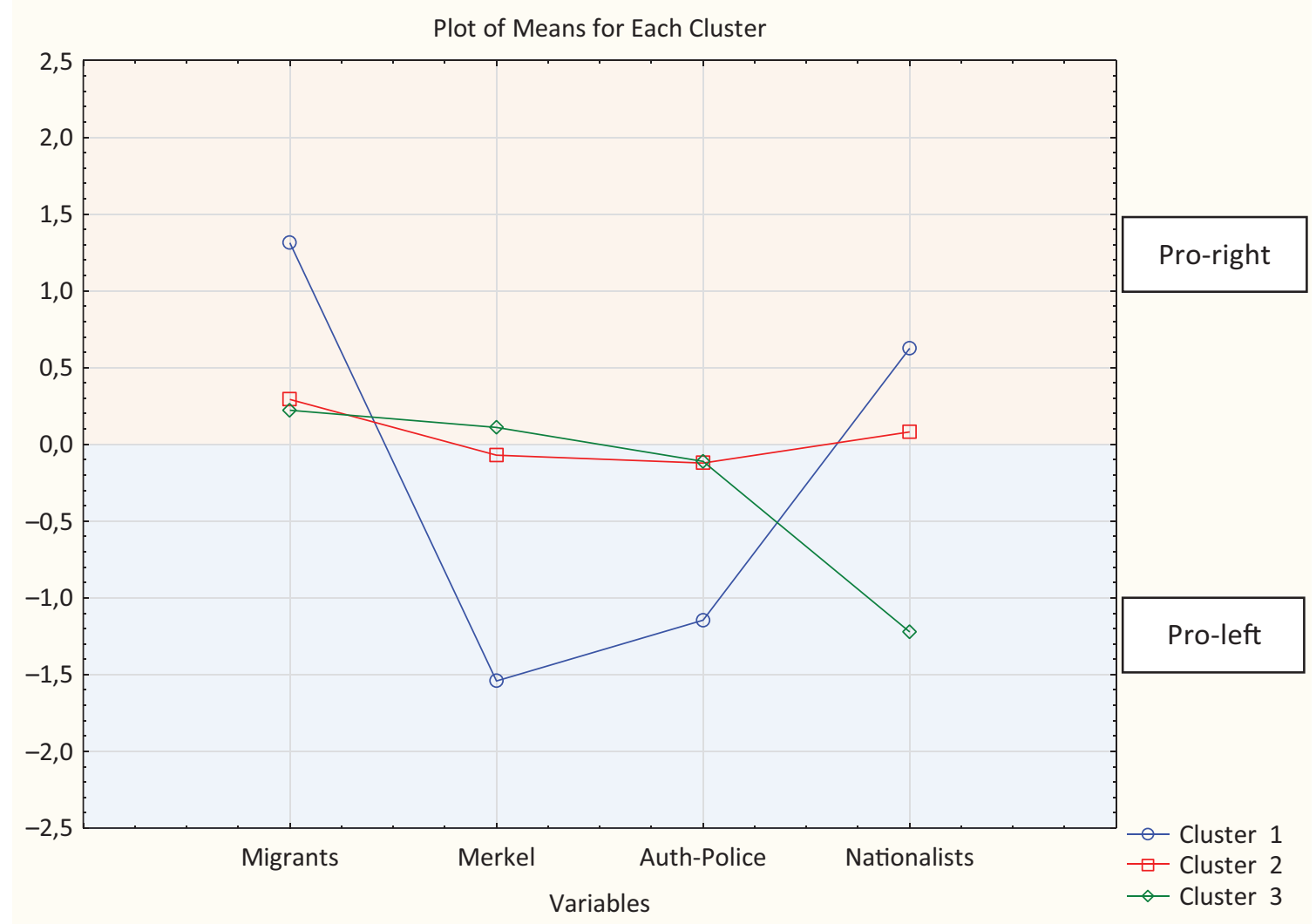

Figure 8. Mean values for the recoded data on user attitudes towards the selected political actors for Germany. 


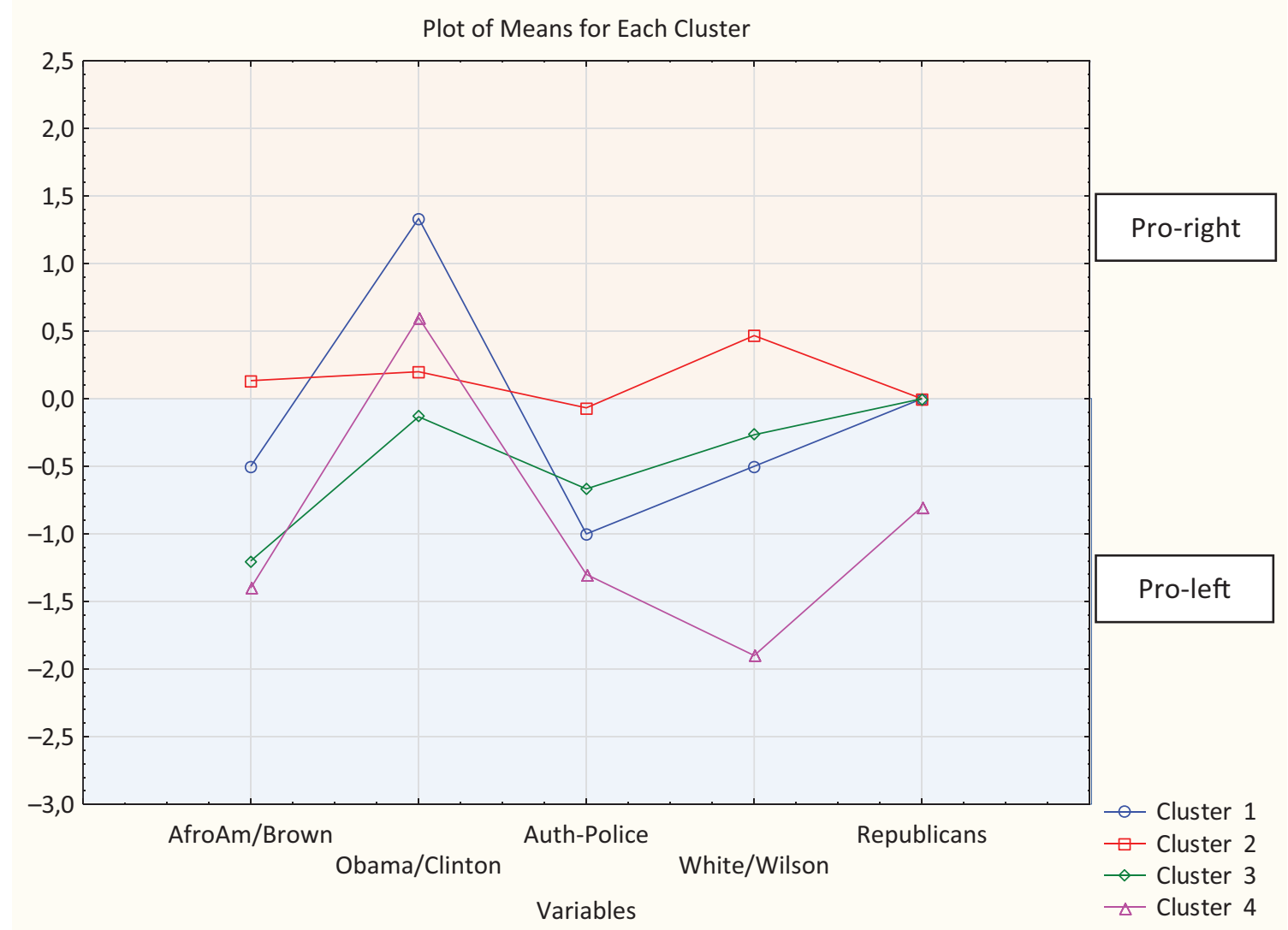

Figure 9. Mean values for the recoded data on user attitudes towards the selected political actors for the USA.

Table 1. Recoding of variables for their left-right normalization.

\begin{tabular}{llcccccc}
\hline Country & Minority & President & Police-Authorities & Nationalists & Opposition & Democrats & Republicans \\
\hline Russia & Recoded & Not & Not & Not & Recoded & - & - \\
Germany & Recoded & Not & Not & Not & - & - & - \\
USA & Recoded & Recoded & Not & Not & - & Recoded & Not \\
\hline
\end{tabular}

actually constituted the discussions. Neither did the group divisions correspond to the minority/pro-minority majority/anti-minority majority scheme. Instead, the clusters may be described as follows:

For Russia, the clusters include: 'news disseminators'; 'anti-establishment nationalists'; and 'angry citizens'. The first group was mostly neutral but formed a substantial part of the political discussions by supplying (posting or retweeting) news at each stage of the conflict. The second cluster was clearly anti-immigrant and nationalistic but differed from European nationalism. Within the discussion, there was also an evident divide between the nationalist groups who supported the current establishment and those who actively opposed it. The former saw the incumbent leadership as the flesh of the 1990s' elites who 'had stolen the country'; such users, therefore, blamed the national policymakers for supporting the post-Soviet immigration. The second type of nationalism - the pro-establishment oneshowed up in the third cluster of 'angry citizens'. This cluster united anti-institutionalists who were raising voices against bespredel ('the absence of limits' and rules of the game), but in differing ways. This diverse group included pro-Putin nationalists who were ready to fight with the Moscow riot police, liberal oppositional media and public figures who criticized the policymakers, and 'tired citizens' who negatively treated the immigrants, and the country leaders, and the local authorities, and the nationalists. Unlike in the 'news disseminators' cluster, the close-to-zero means for these variables here were the result of pro- and anti-establishment views compensating each other while the users united against police (see Figure 1).

For Germany, the clusters include: 'news disseminators'; 'nationalists'; and 'anti-nationalists'. Discursively, the biggest group of 'nationalists' unites two similar sub-groups, one with slightly more aggressive tendencies towards small liberal-oriented parties and activist movements (like Antifa), and the other more critical of the national government. The anti-nationalist group is, however, also salient, making the German picture onedimensional in terms of political divisions (pro- and anti- 
minority), even if the dimension is not political-party but issue-based. Also, the overlappers play a significant role here, as they visually stand in between the two opposing clusters, thus creating bridges for public dialogue (see Figure 5).

For the USA, the clusters include: 'media-oriented users'; 'human rights activists'; 'politicized observers'; and 'whites' blamers' (see Figure 3). Within the influencers, the clusters were similar in volume, but, on the big graph, the last two groups were relatively smallscale, while the first two dominated the graph. Just as in Russia, the media-oriented discourse was a part of the political discussion, but the three other groups were not neutral, especially 'whites' blamers' and 'human rights activists.' The former actively blamed 'the white dominance' and called for action against oppression. Interestingly, the hashtag \#blacklivesmatter was less important for this group than for the media-oriented discourse. However, blaming hashtags and words like 'murderer,' 'republikkklan,' or 'kkkop,' and calls for action (like '\#arrestdarrenwilson,' '\#boycottgofundme,' or '\#donotshopmonday'), were prominent. The other group, very different from 'whites' haters,' and linked the case to human rights issues like abortion (\#prolife), gender inequality (\#womeninequalityday), morality (\#moralmonday), and others. The group itself, as one can see even from the hashtags, was polar in itself in terms of left and right divisions on human rights. For this group, positioning on Mike Brown's death was different, expressed mostly by 'don't shoot' hashtags. 'Politicized observers' abstained from taking clear sides, but discussed the Ferguson events in terms of its influence upon the political process in America. Interestingly, the cluster that mostly reposted media, was the most proWilson, as media, evidently, tried to remain balanced; they also reported police press conferences that were modestly defensive towards Darren Wilson.

Then, we looked at how the discourses we described spread inside the graph. Our task was not to calculate the level of homophily and prove user clustering for all the discussions; the goal was to see how the discourses actually spread and whether they spread in a similar way-and they did not. For Russia and the USA, the discourses mixed, but if in Russia we saw inter-cluster talk, in the USA overlappers took almost all the space in the graph centre. And in Germany, the graph was clearly structurally divided. This was also proved by the mean in- and inter-cluster weighted number of edges: in Russia, the inter-cluster links took over (216 vs. 323.5, respectively), while in Germany (4392.75 vs. 2890.25) and the USA (21114.4 vs. 3755.2 ) in-group connections were stronger.

Thus, the attitude-based grouping was different in each of the three cases. Also, it was far from clear left-right identifications. In order to show it, we have recoded the variables as stated above, making proleft views negative $(-1$ to -2$)$ and pro-right views positive (1 to 2 ). We considered anti-minority, anti-
Obama/Clinton, pro-Putin/Medvedev, pro-Merkel, propolice, pro-nationalist, anti-opposition (in Russia), antiDemocrat, and pro-Republican (in the USA) views proright, while the opposite was marked pro-left. See the full recoding scheme in Table 1.

The resulting graphs of means are quite telling (see Figures 7 to 9). Both in Russia and Germany, the leaders representing rightist sides of the spectra have actually taken pro-migration stance, and this has made right-wing users who support nationalist movements and speak against immigrants, move left and be against the incumbent leaders, as well as against the local authorities and police for 'not protecting' the host communities. But the other clusters in the two countries quite strongly differ from each other. While in Germany issue-based leftism is clearly seen, the other Russian cluster of 'angry citizens' diverges into three discourses that combine clearly rightist, pro-establishment nationalism; liberal, anti-establishment oppositional speakers; and politicised citizens. These politicised citizens, paradoxically for external observers, do not support any of the existing political factions, due to their impotence in resolving local problems. Thus, at least two nationalist discourses were detected by us for Russia-while in the USA there are two very different left-wing clusters, one clearly left, supportive of either Obama or Clinton and based on human rights' discourse, and another that was sharply anti-white, even blaming Obama for not being protective enough, which, in our rough coding, made the cluster stick out to anti-Obama views on the rightist side of Figure 9 (in effect, being extreme left). The cluster of 'politicized observers', interestingly, is reminiscent of the 'tired citizens' in Russia, as they are, on average, only slightly pro-African-American and, more strongly, antileader, anti-police, and anti-majority.

Another crucial observation is that, while the divisions in the discussion clearly stem from local political contexts, they are quite far from expectations determined by the systemic political features of the countries. Thus, in the majoritarian USA where one would expect two-sided polarization, the clusters were, in fact, numerous and the discussion was based on overlappers. It was rather coalitional Germany that showed polarization. And in Russia, just one side of the spectrum was present in the discussion. Thus, it is not only the local political markets but also the nature of the issue and issue-based divisions that shape political clustering.

Overall conclusions are thus the following: The discursive schisms do exist in issue-based discussions, but they do not fall into binary categories according to majoritarian political divisions, and; they only partially fall into the three-side divisions expected by the nature of the issue. Instead, local political spectra may provoke the formation of, for example, two leftist or two rightist clusters. Only Germany has demonstrated the expected divisions between anti- and pro-minority majority, while the minority remained highly under-represented at all, like in Russia-and unlike in America. 
The similarities can also be traced, but not in terms of left and right divisions. First, in all the discussions, a politically neutral news-based cluster played a significant structural role. Second, all three discussions revealed harsh anti-institutionalism, including that from the users who, in conventional logic, were expected to support the incumbents. Third, Germany and Russia were similar in how nationalist clusters were against the conservative governments, and Russia and the USA were similar in how the 'tired citizens' were politicised against all the political sides.

\section{Conclusion}

In our article, we have combined content analysis of social media with cluster analysis and graph construction. Our method has revealed greater complexity of politicised discourse within ad hoc Twitter discussions on interethnic conflicts. Thus, we have found that there may be several clusters of leftist or rightist views even if the number of clusters is minimal, and users may combine formally leftist and rightist views if positions of political actors or the nature of the issue demand it. The groups we have detected differ highly in their conceptualisation from the traditional left and right divisions and left or right labels cannot be attached to individual users based on their preferences, like pro- and anti-minority stances or treatments of country leaders or parties. We have also shown that, on the graphs, the discourses intertwine quite intensely if we do not force the graphs to artificially diverge according to users' political views.

Our research provides new input for rethinking the political divisions that form online, on what grounds they form, and how to detect them. The local political contexts, as well as the nature of the issues under scrutiny, are major factors to be taken into account. In our article, the 'issue publics' provide clues on how political opinion is veering away from traditional left and right divisions, and Twitter communication is more complicated than the imaginary cocooned talk in echo chambers, especially for issues beyond elections and direct policing.

Limitations of our method stem from the subjectivity of coding and from the low number of coded influencers, but these may be partially overcome by automatisation of coding collections and the increase of the number of coded users thanks to automatisation. Our method may be applied to detect hidden issue-oriented polarization beyond one-dimensional left-right political spectra.

\section{Acknowledgments}

We are grateful to Olessia Koltsova (Russia) and Christian Baden (Israel) for their comments on early versions of the article, as well as to our international team of coders. This research has been supported in full by the Russian Science Foundation grant 16-18-10125-P (20162018, prolonged for 2019-2020).

\section{Conflict of Interests}

The authors declare no conflict of interests.

\section{References}

Adamic, L. A., \& Glance, N. (2005). The political blogosphere and the 2004 US election: Divided they blog. In Proceedings of the 3rd international workshop on link discovery (pp. 36-43). New York, NY: ACM.

Agathangelou, P., Katakis, I., Rori, L., Gunopulos, D., \& Richards, B. (2017). Understanding online political networks: The case of the far-right and far-left in Greece. In International conference on social informatics (pp. 162-177). Cham: Springer.

Bakshy, E., Messing, S., \& Adamic, L. A. (2015). Exposure to ideologically diverse news and opinion on Facebook. Science, 348(6239), 1130-1132.

Barberá, P. (2014). How social media reduces mass political polarization. Evidence from Germany, Spain, and the US. Paper prepared for the 2015 APSA Conference, San Francisco, CA, USA. Retrieved from http://pablobarbera.com/static/barbera_ polarization_APSA.pdf

Barberá, P., Jost, J. T., Nagler, J., Tucker, J. A., \& Bonneau, R. (2015). Tweeting from left to right: Is online political communication more than an echo chamber? Psychological Science, 26(10), 1531-1542.

Barberá, P., \& Rivero, G. (2015). Understanding the political representativeness of Twitter users. Social Science Computer Review, 33(6), 712-729.

Blekanov, I. S., Sergeev, S. L., \& Martynenko, I. A. (2012). Constructing topic-oriented web crawlers with generalized core. Scientific and Research Bulletin of St. Petersburg State Polytechnic University, 5(157), 9-15.

Bluhm, K., \& Varga, M. (2018). New conservatives in Russia and East Central Europe. Abingdon: Routledge.

Bodrunova, S. S. (2018). When context matters. Analyzing conflicts with the use of big textual corpora from Russian and international social media. Partecipazione e Conflitto, 11(2), 497-510.

Bodrunova, S. S., Blekanov, I. S., \& Maksimov, A. (2017). Measuring influencers in Twitter ad-hoc discussions: Active users vs. internal networks in the discourse on Biryuliovo bashings in 2013. In 2016 IEEE artificial intelligence and natural language conference (AINL) (pp. 1-10). Piscataway, NJ: IEEE.

Bodrunova, S. S., Litvinenko, A. A., \& Blekanov, I. S. (2017). Comparing influencers: Activity vs. connectivity measures in defining key actors in Twitter ad hoc discussions on migrants in Germany and Russia. In International conference on social informatics (pp. 360-376). Cham: Springer.

Bodrunova, S. S., Litvinenko, A. A., \& Blekanov, I. S. (2018). Please follow us: Media roles in Twitter discussions in the United States, Germany, France, and Russia. Journalism Practice, 12(2), 177-203.

Bramson, A., Grim, P., Singer, D. J., Fisher, S., Berger, W., 
Sack, G., \& Flocken, C. (2016). Disambiguation of social polarization concepts and measures. The Journal of Mathematical Sociology, 40(2), 80-111.

Bruns, A., \& Burgess, J. E. (2011). The use of Twitter hashtags in the formation of ad hoc publics. In Proceedings of the 6th ECPR general conference 2011. Retrieved from http://eprints.qut.edu.au/46515/1/ The_Use_of_Twitter_Hashtags_in_the_Formation_ of_Ad_Hoc_Publics_(final).pdf

Colleoni, E., Rozza, A., \& Arvidsson, A. (2014). Echo chamber or public sphere? Predicting political orientation and measuring political homophily in Twitter using big data. Journal of Communication, 64(2), 317-332.

Conover, M., Ratkiewicz, J., Francisco, M. R., Gonçalves, B., Menczer, F., \& Flammini, A. (2011). Political polarization on Twitter. In Proceedings of the Fifth International AAAl Conference on Weblogs and Social Media (ICWSM) (pp. 89-96). Retrieved from https://www.aaai.org/ocs/index.php/ICWSM/ ICWSM11/paper/view/2847

Dang-Xuan, L., Stieglitz, S., Wladarsch, J., \& Neuberger, C. (2013). An investigation of influentials and the role of sentiment in political communication on Twitter during election periods. Information, Communication \& Society, 16(5), 795-825.

Daniels, J. (2013). Race and racism in Internet studies: A review and critique. New Media \& Society, 15(5), 695-719.

Duca, J. V., \& Saving, J. L. (2017). Income inequality, media fragmentation, and increased political polarization. Contemporary Economic Policy, 35(2), 392-413.

Elgesem, D. (2017). Polarization in blogging about the Paris meeting on climate change. In International conference on social informatics (pp. 178-200). Cham: Springer.

Elgesem, D., Steskal, L., \& Diakopoulos, N. (2015). Structure and content of the discourse on climate change in the blogosphere: The big picture. Environmental Communication, 9(2), 169-188.

Esteban, J. M., \& Ray, D. (1994). On the measurement of polarization. Econometrica: Journal of the Econometric Society, 62(4), 819-851.

Evolvi, G. (2017). \#Islamexit: Inter-group antagonism on Twitter. Information, Communication \& Society, 22(3), 1-16.

Guerra, P. H. C., Meira, W., Jr., Cardie, C., \& Kleinberg, R. (2013). A measure of polarization on social media networks based on community boundaries. In Proceedings of the Seventh international AAAl conference on weblogs and social media (ICWSM) (pp. 214-224). Menlo Park, CA: AAAI Press.

Guerra, P. H. C., Veloso, A., Meira, W., Jr., \& Almeida, V. (2011). From bias to opinion: A transfer-learning approach to real-time sentiment analysis. In Proceedings of 17th ACM SIGKDD international conference on knowledge discovery and data mining (pp. 150-158). New York, NY: ACM.

Hillmann, R., \& Trier, M. (2012). Sentiment polariza- tion and balance among users in online social networks. In AMCIS 2012 Proceedings, 2012(10). Retrieved from http://aisel.aisnet.org/amcis2012/ proceedings/VirtualCommunities/10

Isenberg, D. J. (1986). Group polarization: A critical review and meta-analysis. Journal of Personality and Social Psychology, 50(6), 1141.

Martin, S., Brown, W. M., Klavans, R., \& Boyack, K. W. (2011). OpenOrd: An open-source toolbox for large graph layout. In Visualization and Data Analysis, 7868, 786-806.

McCright, A. M., \& Dunlap, R. E. (2011). The politicization of climate change and polarization in the American public's views of global warming, 2001-2010. The Sociological Quarterly, 52(2), 155-194.

Morales, A. J., Borondo, J., Losada, J. C., \& Benito, R. M. (2015). Measuring political polarization: Twitter shows the two sides of Venezuela. Chaos: An Interdisciplinary Journal of Nonlinear Science, 25(3), 033114.

Packer, D. J. (2008). On being both with us and against us: A normative conflict model of dissent in social groups. Personality and Social Psychology Review, 12(1), 50-72.

Packer, D. J., \& Chasteen, A. L. (2010). Loyal deviance: Testing the normative conflict model of dissent in social groups. Personality and Social Psychology Bulletin, 36(1), 5-18.

Papacharissi, Z. (2015). Affective publics: Sentiment, technology, and politics. Oxford: Oxford University Press.

Rivero, G. (2017). Preaching to the choir: Ideology and following behaviour in social media. Contemporary Social Science, 14(1), 54-70.

Speriosu, M., Sudan, N., Upadhyay, S., \& Baldridge, J. (2011). Twitter polarity classification with label propagation over lexical links and the follower graph. In Proceedings of the first workshop on unsupervised learning in NLP (pp. 53-63). Cambridge, MA: Association for Computational Linguistics.

Stieglitz, S., \& Dang-Xuan, L. (2012). Political communication and influence through microblogging: An empirical analysis of sentiment in Twitter messages and retweet behavior. In 45th Hawaii international conference on system science (pp. 3500-3509). Piscataway, NJ: IEEE.

Sunstein, C. (2002). The law of group polarization. Journal of Political Philosophy, 10(2), 175-195.

Tajfel, H., \& Turner, J. C. (1979). An integrative theory of intergroup conflict. In W. G. Austin \& S. Worchel (Eds), The social psychology of intergroup relations (pp. 33-37). Monterey: Brooks/Cole.

United Nations. (2013). Trends in international migrant stock: The 2013 revision. New York, NY: United Nations. Retrieved from http://www.un.org/en/ development/desa/population/migration/data/ estimates2/estimatestotal.shtml

United Nations. (2017). Trends in international migrant stock: The 2017 revision. New York, NY: United Nations. Retrieved from https://www.un.org/en/ 
development/desa/population/migration/data/ estimates2/estimatestotal.asp

Weber, I., Garimella, V. R. K., \& Batayneh, A. (2013). Secular vs. Islamist polarization in Egypt on Twitter. In Proceedings of the 2013 IEEE/ACM international con- ference on advances in social networks analysis and mining (pp. 290-297). New York, NY: ACM.

Yardi, S., \& Boyd, D. (2010). Dynamic debates: An analysis of group polarization over time on Twitter. Bulletin of Science, Technology \& Society, 30(5), 316-327.

\section{About the Authors}
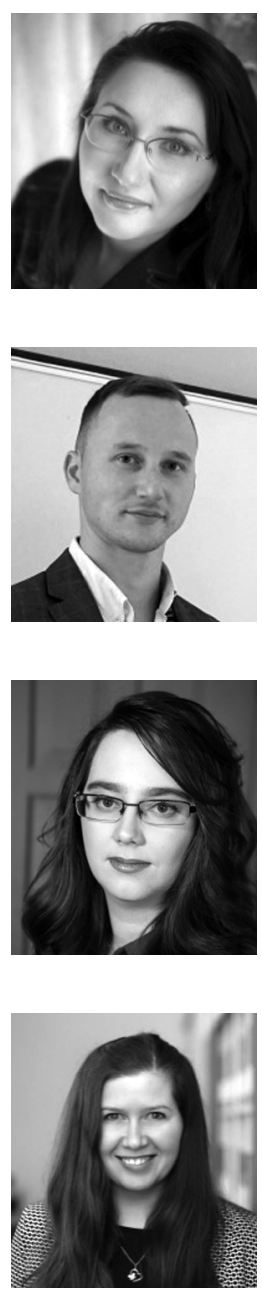

Svetlana S. Bodrunova is habilitated Doctor of Political Science and Professor at School of Journalism and Mass Communications, St. Petersburg State University, Russia. She has lead six research projects and published two books, several chapters, and over 80 research papers in Russian and English on Russian and European journalism, media and politics, social media, and ethnicity in communication. She leads the Center for International Media Research in her university.

Ivan Blekanov has PhD in System Analysis, Control and Data Processing. He is Assistant Professor and Head of Department of Programming Technology at St. Petersburg State University, Russia. He has published over 40 academic publications in Russian and English and has lead data science teams within 5 interdisciplinary projects. His research interests include information retrieval and data mining, webometrics and web analytics, social network analysis and computer forensics. He also works as IT industry consultant.

Anna Smoliarova is Associate Professor of School of Journalism and Mass Communications at St. Petersburg State University. Her research interests include media and migration studies, mainly focusing on immigrant media of modern Russian-speaking diaspora in the world; media consumption and media choice; individual and collective behaviors of social media users. She is head of the research project 'Media consumption among Russian-speaking immigrants' (2018-2019).

Anna Litvinenko, PhD, is Researcher in the Emmy Noether Junior Research Group 'Mediating (Semi-)Authoritarianism: The Power of the Internet in the Post-Soviet Region' at Free University of Berlin. After receiving her PhD in 2007, she worked as Associate Professor at the Department of International Journalism of St. Petersburg State University, Russia. Her research focusses on the interrelation of media and politics in the digital age and on the role of social media platforms in various socio-political contexts. 